\title{
Publisher Correction: Inhibitory circuit gating of auditory critical-period plasticity
}

Anne E. Takesian, Luke J. Bogart, Jeff W. Lichtman and Takao K. Hensch (D)

Correction to: Nature Neuroscience https://doi.org/10.1038/s41593-017-0064-2, published online 22 January 2018.

In the version of this article initially published online, the wrong version of Fig. 5 was used. There were errors in the statistical comparison brackets in Fig. $5 \mathrm{c}$ and the left-hand error bar in Fig. 5f. The errors have been corrected in the print, PDF and HTML versions of this article. In the version of this article initially published online and in print, the wrong version of Fig. $3 \mathrm{~h}$ was used. There was a slight error in the alignment of the traces in the top right panel. The error has been corrected in the PDF and HTML versions of this article.

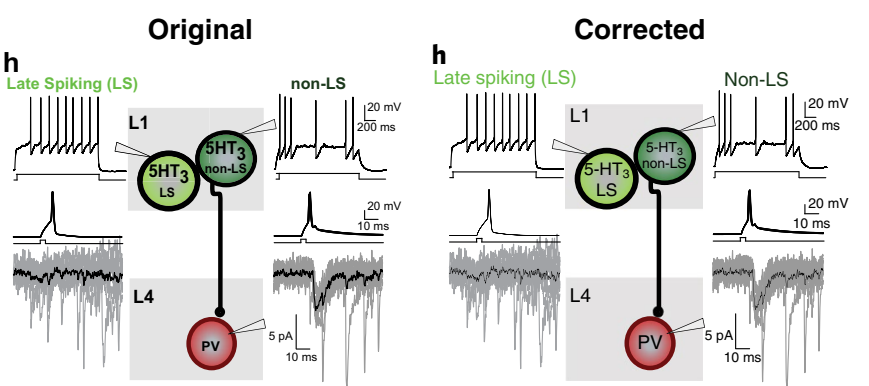

Fig. 3 | Original and corrected.
Original

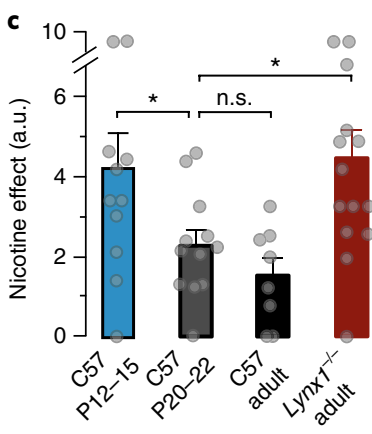

$\mathbf{f}$
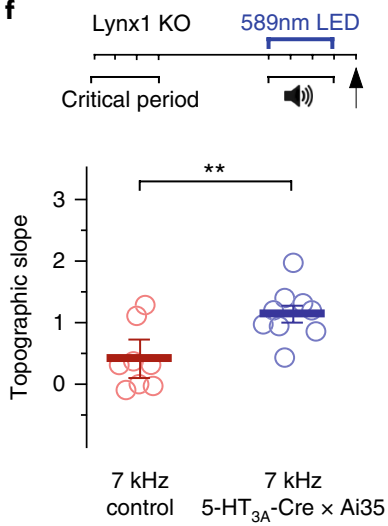

Fig. 5 | Original and corrected.
Corrected

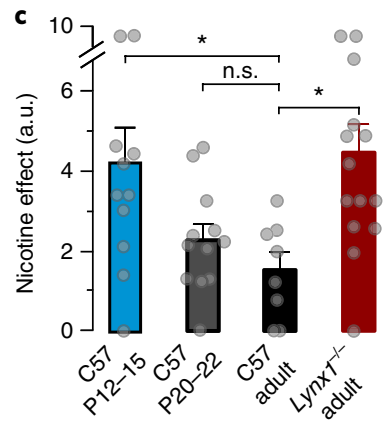

$\mathbf{f}$
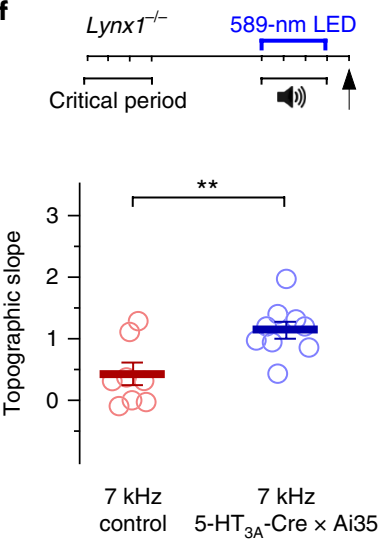

control $\quad 5-\mathrm{HT}_{3 \mathrm{~A}}-\mathrm{Cre} \times \mathrm{Ai} 35$

Published online: 18 June 2018

https://doi.org/10.1038/s41593-018-0161-x 